\title{
Genetic linkage map construction and QTL identification of juvenile growth traits in Torreya grandis
}

\author{
Yanru Zeng ${ }^{1 *}$, Shengyue $\mathrm{Ye}^{1}$, Weiwu Yu${ }^{1}$, Song $\mathrm{Wu}^{2}$, Wei $\mathrm{Hou}^{3}$, Rongling $\mathrm{Wu}^{4^{*}}$, Wensheng Dai ${ }^{1}$, Jun Chang $^{5}$ \\ From International Symposium on Quantitative Genetics and Genomics of Woody Plants \\ Nantong, China. 16-18 August 2013
}

\begin{abstract}
Torreya grandis Fort. ex Lindl, a conifer species widely distributed in Southeastern China, is of high economic value by producing edible, nutrient seeds. However, knowledge about the genome structure and organization of this species is poorly understood, thereby limiting the effective use of its gene resources. Here, we report on a first genetic linkage map for Torreya grandis using 96 progeny randomly chosen from a half-sib family of a commercially cultivated variety of this species, Torreya grandis Fort. ex Lindl Cv. Merrillii. The map contains 262 molecular markers, i.e., 75 random amplified polymorphic DNAs (RAPD), 119 inter-simple sequence repeats (ISSR) and 62 amplified fragments length polymorphisms (AFLP), and spans a total of 7,139.9 cM, separated by 10 linkage groups. The linkage map was used to map quantitative trait loci (QTLs) associated with juvenile growth traits by functional mapping. We identified four basal diameter-related QTLs on linkage groups 1, 5 and 9; four heightrelated QTLs on linkage groups 1, 2, 5 and 8. It was observed that the genetic effects of QTLs on growth traits vary with age, suggesting the dynamic behavior of growth QTLs. Part of the QTLs was found to display a pleiotropic effect on basal diameter growth and height growth.
\end{abstract}

\section{Introduction}

Plant breeding has proven to be difficult because most economically important traits are quantitatively inherited, controlled by an interacting network of genes, each with a small effect, and environmental factors. This is especially true for forest trees, a group of species characterized by long life spans, high heterozygosity, and environmental heterogeneity $[1,2]$. It is ubiquitous that variation in phenotypic traits of forest trees fluctuates from year to year owing to varying contributions from genetic and environmental factors. Molecular technologies extensively developed in the past several decades have provided a powerful tool to dissert phenotypic variation into its underlying genetic factors, known as

\footnotetext{
* Correspondence: yrzeng@zafu.edu.cn; RWU@phs.psu.edu

'The Nurturing Station for the State Key Laboratory of Subtropical Silviculture, Zhejiang Agricultural and Forestry University, Lin'an, Zhejiang 311300, China

${ }^{4}$ Center for Statistical Genetics, Pennsylvania State University, Hershey, PA 17033, USA

Full list of author information is available at the end of the article
}

quantitative trait loci (QTLs) [3-5]. Genetic mapping of QTLs from linkage maps has become a routine avenue to identify and study the genetic architecture of phenotypic traits [6].

There has been a considerable body of literature on the construction of genetic maps in forest trees, such as Eucalyptus [7], Salix [8], Betula [9], Populus [10-12], and Pinus $[13,14]$. Because it is difficult or impossible to obtain segregating populations from inbred lines, genetic mapping in forest trees should use strategies that are different from those used in annual crops or model systems. These strategies include (1) controlled crosses made from two heterozygous parents, in which different types of markers are segregating [15-17], and (2) open-pollinated progeny from a heterozygous tree, consisted of seeds that share the same mother but have different fathers [14,18]. In gymnosperms including conifers, cycads, ginkgo, and Gnetales, a seed consists of a diploid seed coat from the original parent sporophyte, a haploid megagametophyte developed from a megaspore produced 
by the original sporophyte, and a diploid embryo developed from the fertilization of the original sporophyte and a male sporophyte [19]. Given its haploid feature, less expensive dominant markers genotyped on the megagametophyte are equally informative to more expensive codominant markers and, therefore, the megagametophyte has been widely used as a tissue to generate molecular markers for genetic mapping.

By taking advantage of megagametophyte-based genotyping, we constructed a low-density genetic linkage map for an important but understudied conifer species, Torreya grandis Fort. ex Lindl, using dominant markers. The genus Torreya comprises 8 dioecious species, 5 of which originate in China [20]. T. grandis cv. Merrillii is the only commercially important ever-green variety for nut production. Despite its widespread cultivation in Southeastern China for thousands of years, however, the genetic background of this variety has been poorly understood. In T. grandis and T. grandis cv. Merrillii, only several protocols have been established for molecular marker assays [21-24]. A limited set of markers has been used to estimate genetic relatedness among several varieties [25] and identify sexes in young seedlings [26,27].

The genetic map reported in this study is a first one for Torreya grandis. This map was constructed from an openpollinated progeny, composed of half-sibs, produced from Torreya grandis Fort. ex Lindl cv. Merrillii. While markers were genotyped from haploid megagametophyte, phenotypic traits were measured from the seedlings of these halfsibs generated from the diploid embryos. Wu [18] derived a statistical model for mapping QTLs for diploid issues using megagametophyte-based markers. We used this model to map QTLs that control stem height and base diameter growth in juvenile seedlings. The dynamic pattern of QTL effects detected was studied by functional mapping, a statistical model for QTL mapping of developmental trajectories [28-32]. The identification of growth QTLs may provide scientific guidance for marker-assisted selection of economically important traits in Torreya grandis.

\section{Results}

\section{Map construction}

The 16 primers screened from five random samples generated a total of 109 markers, 91 of which $(82 \%)$ were polymorphic. The number of polymorphic RAPD markers produced per primer ranged from 2 to 11, with an average of 5.7. ISSR analysis using 24 primers created 194 polymorphic loci in total on the genomic DNAs, with an average of 8 loci per primer. Fifteen polymorphic loci were amplified using primer ISSR-46, but only two using ISSR-52. For AFLP analysis, 14 pairs of selective primers generated 155 polymorphic loci, with E6/M4 amplifying 24 polymorphic loci while E2/M7 and E4/M5 amplifying three only, and an average of polymorphic loci produced by a pair of primers is 11 . In total, three different types of markers generated 440 polymorphic loci.

Of all the markers, 262 (75 RAPDs, 119 ISSRs and 68 AFLPs) (59\%) were identified to follow Mendelian segregation ratio according to chi-square tests at a level of $\geq=0.05$. These markers were mapped to 10 linkage groups at an LOD $>6$ with Mapmaker 3.0. The total map distance was $7,138 \mathrm{cM}$ (Kosambi units) with an average distance between adjacent markers of $28.2 \mathrm{cM}$ (Figure 1). Linkage groups each comprise 7 - 71 loci $(138-1898.5 \mathrm{cM})$. Table 1 shows the distribution of markers in different linkage groups. Our long map constructed in Torreya grandis cv. Merrillii confirms the detection of large genomes of coniferous species.

\section{Detection of growth QTL}

Growth curves of 510 young seedlings from the openpollinated population over the first three years are illustrated in Figure 2, where substantial variation in curve shape exists, suggesting that specific QTLs may be involved in developmental trajectories. Functional mapping was used to scan the existence and distribution of QTLs for growth traits by calculating genome-wide likelihood ratios (LR) of the full model with a QTL and the reduced model without QTL (Figure 3). By comparing the LR peaks with chromosome-wide critical thresholds determined from permutation tests, we identified several significant QTLs for stem diameter and height growth. As a first QTL study in $T$. grandis, we used a less conservative criterion at the chromosome level to claim the significance of QTLs. Four significant QTLs for stem diameter growth were detected in marker intervals S11-2 - E8M8-2 on linkage group 1, I-77-3 - I-36-6 in linkage group 5, I-17-8 - I-44-9 and E6M5-11 - E8M8-1in linkage group 9. Four significant QTLs for stem height are located between markers I-5610 - I-46-10 on linkage group 1, I-46-13 - E6M4-5 on linkage group 2, E6M7-2 - I-34-6 on linkage group 5 and E6M8-6 - E7M3-12 on linkage group 8. Linkage group 1 and 5 carry the QTLs for both diameter and height growth, suggesting that these segments may contribute to the genetic correlation between these two growth traits.

Using the estimated growth parameters, we drew growth curves of each QTL identified for height and diameter traits (Figure 4A). In general, all genotypes increase in both height and basal diameter with age, although the extent of increase varies depending on the QTL detected. For the height QTLs detected in linkage groups 1,2 , and 8 , favorable alleles for increasing stem height are derived from the egg of T. grandis cv. Merrillii, whereas the favorable allele at the QTL detected in linkage group 5 is from a pollen which may be generated by either T. grandis cv. Merrillii or another tree in the pool. For the diameter QTLs on linkage groups 1 and 5, the egg of T. grandis cv. Merrillii contributes favorable alleles 
Figure 1 Genetic linkage map constructed from 75 RAPD, 119 ISSR and 68 AFLP markers for 96 half-sib seedlings derived from a maternal parent in Torreya grandis cv. Merrillii.

for increasing radial growth, whereas two QTLs on linkage group 9 have their favorable alleles from the pollen. As seen in Figure 4B, genetic effects on both diameter and height growth increase with age during the early stage of growth.

\section{Discussion}

Despite its economic, ornamental and ecological importance, the genetic study of Torreya grandis has received little attention. For those underrepresented tree species like T. grandis, for which little knowledge about their genome structure and sequence is available, simple and cheap dominant markers have still been widely used for constructing genetic linkage maps. In this article, we present a first linkage map for $T$. grandis constructed from three types of dominant markers, RAPD, ISSR and AFLP. A total of 262 markers are clustered into 10 linkage groups, totaling 7,138 cM in length. Since T. grandis

Table 1 Distribution of molecular markers on 10 linkage groups for a half-sib family of Torreya grandis cv. Merrillii.

\begin{tabular}{|c|c|c|c|c|c|c|c|c|}
\hline Linkage Group & No. Markers & RAPD & ISSR & AFLP & Max. Distance & Min. Distance & Length & Ave. Distance \\
\hline LG1 & 71 & 6 & 59 & 6 & 64.7 & 3.5 & 1898.5 & 27.1 \\
\hline LG2 & 46 & 6 & 24 & 16 & 75.5 & 4.2 & 1492.2 & 33.2 \\
\hline LG3 & 35 & 23 & 2 & 10 & 78.4 & 2.1 & 915.9 & 26.9 \\
\hline LG4 & 54 & 35 & 18 & 1 & 64.7 & 1 & 1394.4 & 26.4 \\
\hline LG5 & 12 & 1 & 5 & 6 & 53.7 & 14.3 & 397.3 & 36.1 \\
\hline LG6 & 8 & 0 & 0 & 8 & 50.7 & 8.2 & 253.2 & 36.2 \\
\hline LG7 & 8 & 4 & 4 & 0 & 40.9 & 3.5 & 138 & 19.7 \\
\hline LG8 & 8 & 0 & 1 & 7 & 36.9 & 7 & 140.6 & 20.1 \\
\hline LG9 & 11 & 0 & 4 & 7 & 53.7 & 9.4 & 284.4 & 28.4 \\
\hline LG10 & 9 & 0 & 2 & 7 & 50.7 & 4.7 & 223.4 & 27.9 \\
\hline
\end{tabular}




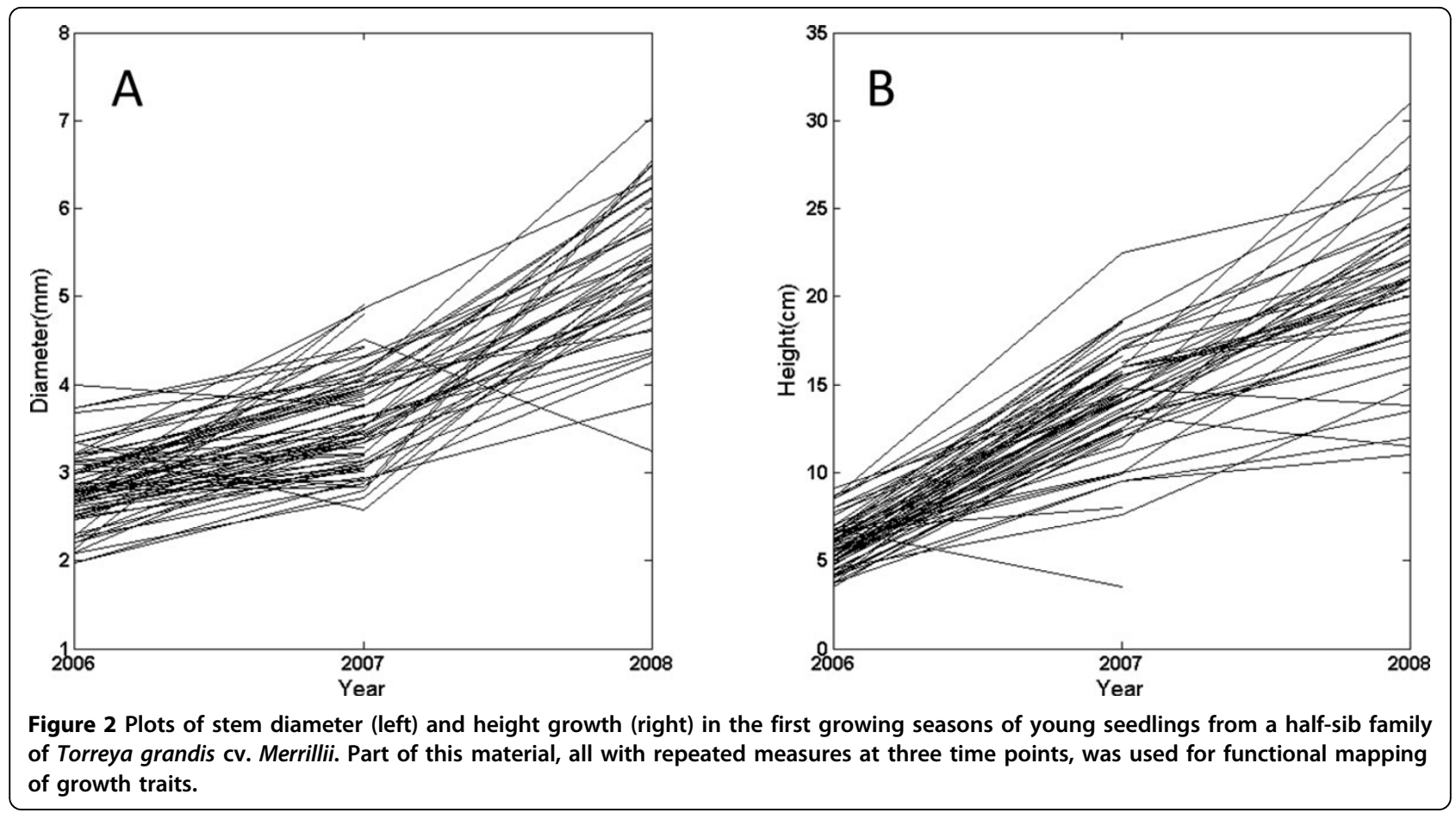

cv. Merrillii has a chromosome number of $2 \mathrm{n}=2 \mathrm{x}=22$ [33], our map only partially covers the genome of T. grandis. Also, given its large marker intervals, our map is quite sparse which should be filled by more markers, especially more informative codominant markers. Nevertheless, a long genetic map identified in our study appears to support the big genome of a gymnosperm $[34,35]$. This map provides an additional fuel to study the structure, organization and evolution of conifer genomes.

We used the linkage map constructed to identify several QTLs for height and radial growth by functional mapping. Although the results presented in this article are preliminary, our study is characterized by two features which are particularly important in genetic mapping of forest trees. First, our mapping design is based on half-sibs from an open-pollinated individual tree in a natural stand. This design can overcome the limitation of genetic mapping for forest trees. Second, while many QTL mapping studies result from the association between markers and phenotypes observed at static points, our method makes use of growth data longitudinally measured at multiple time points through functional mapping [28-32]. Since it was first proposed in 2002, functional mapping has been used to detect growth QTLs in poplar [36] rice [37] and mouse [38]. Its tremendous advantage lies in its integration of biologically meaningful growth equations [39] into QTL mapping, leading to interpretable results of QTL discoveries [40]. All the QTLs identified in this study change their genetic effects over time, with some decreasing while the other increasing.

Powerful genetic and molecular tools have made it possible not only to detect the action of genes at the juvenile stage but also to detect their dynamic actions and interaction of individual loci or QTLs, which is of significance to seedling production in both agriculture and forestry. It has been well known that phenotypic formation results from coordinated action of genes and environmental factors. Based on a better understanding of gene actions, we can design an optimal strategy for seedling selection and production in the first few years in the nursery. Such a strategy is especially important for tree species of highly economic values, like $T$. grandis.

The design used is a half-sib family with members from a heterozygous tree $[14,18]$. A more powerful design is to sample multiple heterozygous trees randomly from a natural population and further collect open-pollinated seeds from each sampled tree [41]. This design constructs a two-stage hierarchical platform composed of the maternal genotypes and offspring genotypes. Wu et al. [41] implemented a sophisticated procedure of the EM algorithm to provide the simultaneous estimates of linkage disequilibria in natural populations and the QTL-marker linkage based on offspring genotypes. Such a design integrating population genetics and quantitative genetics is especially suitable for genetic mapping in T. grandis. More recently, Sun et al. [42] embedded genetic imprinting into this design, enabling geneticists to chart a comprehensive picture of the genetic architecture of growth 


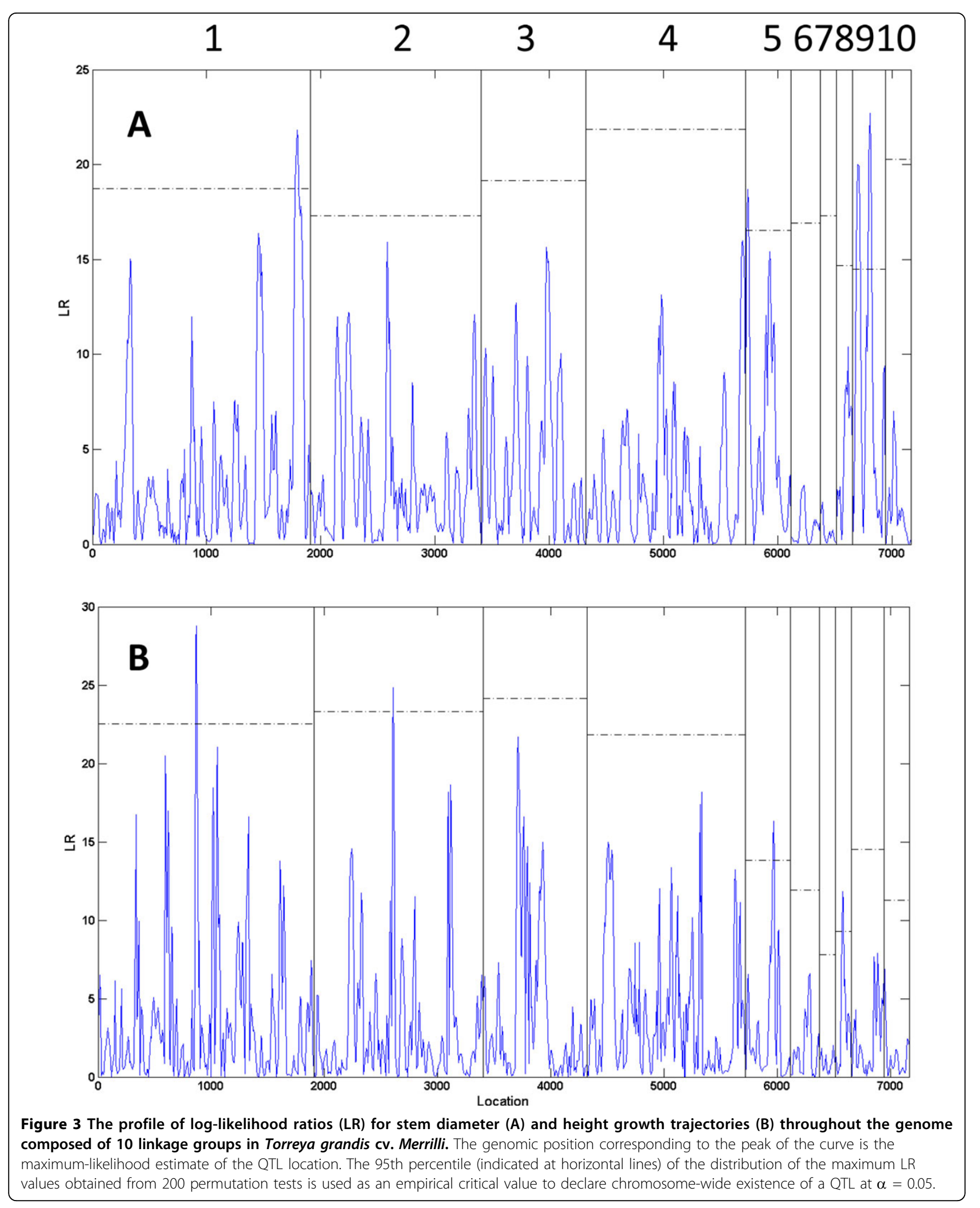




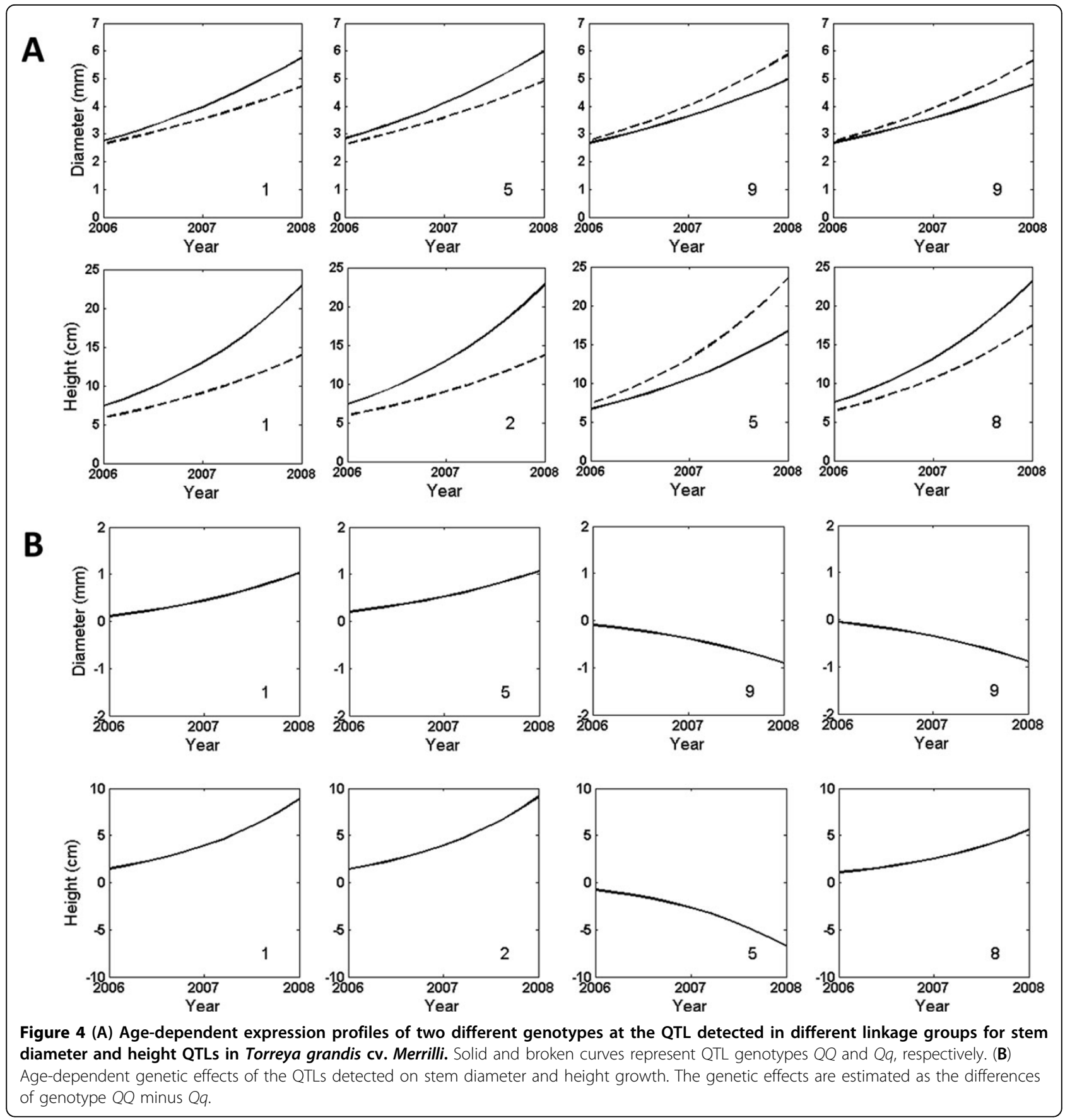

and morphological traits in forest trees, including T. grandis.

\section{Materials and methods}

\section{Plant material}

The mapping population consisted of 510 half-sib progeny of $T$. grandis cv. Merrillii from a relatively isolated, open pollinated tree located in Changming Village, Sankou Town, Lin'an City, Zhejiang Province of China. The seeds harvested were piled for 7 days to soften and remove outermost arils and then stratified with sand in an open area to accelerate germination with two layers of plastic film covering on the pile top of the stratified seeds. When the radicle appeared, the seeds were potted in medium (peat: perlite: vermiculitm $=1: 1: 1$ ), followed by partial megagametophyte extraction from germinating seedlings when seedlings were out of top medium. The white megagametophytes extracted were stored at $-40^{\circ} \mathrm{C}$ for DNA isolation later. If megagametophytes are insufficient, fresh young leaves were harvested for DNA isolation. Juvenile 
growth traits, including seedling height, basal diameter and branching number, were measured consecutively for 3 years at the end of each year.

\section{Molecular marker analysis}

DNA was extracted from both the megagametophytes and young leaves of 96 seedlings by a CTAB method. The quality of DNA extracted was tested by measurement with NanoDrop Sepectrophotomter ND-100 and electrophoresis on $1 \%$ agarose gels, based on which the DNA concentration was calculated. The DNAs of the 96 samples were used for RAPD, ISSR and AFLP analyses.

From 100 primers tested in five random samples, a total of 16 RAPD primers were found to produce polymorphic markers. Amplifications were carried out in 20 - $\mu \mathrm{l}$ aliquots of the solution containing $12.99 \mu \mathrm{l} \mathrm{H} \mathrm{H}_{2} \mathrm{O}$, $2 \mu \mathrm{l} 10 \times$ buffer, $1.76 \mu \mathrm{l} 25 \mathrm{mM} \mathrm{MgCl}, 0.3 \mu \mathrm{l} 10 \mathrm{mM}$ solution of mixed dNTPs (Sangon Biotech (Shanghai) Co., Ltd.), $0.75 \mu \mathrm{l} 10 \mu M$ primer, $2 \mu \mathrm{l}$ of a $10 \mathrm{ng} / \mu \mathrm{l}$ DNA solution, and $0.2 \mu \mathrm{l} 5 \mathrm{U} / \mu \mathrm{l} \mathrm{Taq}$ DNA polymerase (TaKaRa Biotechnology (Dalian) Co., Ltd.). Amplifications were performed in a GeneAmp PCR System 9600 (Applied Biosystem, Singapore) programmed for 40 amplification cycles $\left(94^{\circ} \mathrm{C}\right.$ for $0.5 \mathrm{~min}, 35.2^{\circ} \mathrm{C}$ for $1.5 \mathrm{~min}$, and $72^{\circ} \mathrm{C}$ for $1.5 \mathrm{~min}$ ) followed by 7 -min extension at $72^{\circ} \mathrm{C}$. Amplification products were resolved by electrophoresis on a gel of $1 \%$ agarose run at $110 \mathrm{~V}$ for $45 \mathrm{~min}$ in $1 \times \mathrm{TBE}$ buffer. Band sizes were estimated by comparison to a GeneRuler 100bp DNA Ladder (Fermentas). Gels were stained with ethidium bromide (EB) and photographed on an Alpha Imager (Alpha Innotech Corporation, USA), and the segregation patterns were scored manually as a band being present or absent from a computer printout. The RAPD markers were denoted by their primer code followed by the numbering of the band (e.g. S30-8).

An AFLP analysis protocol was optimized based on description by Vos et al. (1995). A $20 \mu \mathrm{l}$ aliquot containing 250-ng genomic DNA, $2 \mu \mathrm{l} 10 \times$ NE-Buffer 2, $0.2 \mu \mathrm{l}$ $100 \times \mathrm{BSA}$, and $12.35 \mu \mathrm{H}_{2} \mathrm{O}$ was digested with the restriction enzymes viz. $0.15 \mu \mathrm{l}$ of a $20 \mathrm{U} / \mu \mathrm{l}$ EcoRI (New England Biolabs) and $0.3 \mu \mathrm{l}$ of a $10 \mathrm{U} / \mu \mathrm{l} \mathrm{Mse}$ (New England Biolabs) at $37^{\circ} \mathrm{C}$ for $5 \mathrm{~h}$ followed by incubation at $65^{\circ} \mathrm{C}$ for $15 \mathrm{~min}$ to inactivate the enzyme. The DNA digested fragments in the $20 \mu \mathrm{l}$ aliquot were then ligated at $16^{\circ} \mathrm{C}$ for 12 hours to $1.4 \mu \mathrm{l}$ of $\mathrm{M}$-adaptor $(50 \mathrm{p} M)$ and $1.0 \mu \mathrm{l}$ of E-adaptor $(5 \mathrm{p} M)$ contained in a $5 \mu \mathrm{l}$ aliquot of $0.1 \mu \mathrm{l}$ of a $350 \mathrm{U} / \mu \mathrm{l}$ T4 ligase (TaKaRa Biotechnology (Dalian) Co., Ltd.) and $2.5 \mu \mathrm{l} 10 \times \mathrm{T} 4$ ligase buffer followed by a 10-min enzyme inactivation at $65^{\circ} \mathrm{C}$. The pre-selective amplification cycle was carried out in a GeneAmp PCR System 9600 (Applied Biosystem, Singapore) programmed for 25 amplification cycles $\left(94^{\circ} \mathrm{C}\right.$ for $0.5 \mathrm{~min}, 56^{\circ} \mathrm{C}$ for $1 \mathrm{~min}$, and $72^{\circ} \mathrm{C}$ for $1 \mathrm{~min}$ ) followed by 5 -min extension at $72^{\circ} \mathrm{C}$ with one selective nucleotide (E-A, M-C) in an $20 \mu \mathrm{l}$ aliquot containing $2 \mu \mathrm{l}$ digested fragment solution, $1.5 \mu \mathrm{l}$ M-primer $(10 \mathrm{mM}), 1.5 \mu \mathrm{l}$ E-primer $(10 \mathrm{mM}), 2.0 \mu \mathrm{l}$ $10 \times$ PCR buffer, $1.2 \mu \mathrm{l} 25 \mathrm{mM} \mathrm{MgCl} 2,0.3 \mu \mathrm{l} 5 \mathrm{U} / \mu \mathrm{l} \mathrm{Taq}$ polymerase (TaKaRa Biotechnology (Dalian) Co., Ltd.), $1.0 \mu \mathrm{l} 10 \mathrm{~m} M$ solution of mixed dNTPs (Sangon Biotech (Shanghai) Co., Ltd.), and $10.5 \mu \mathrm{l} \mathrm{H}_{2} \mathrm{O}$. The pre-selective amplification product was diluted at 1:30 to be used as a template in the following selective amplification. The selective amplification was programmed for initially denaturing at $94^{\circ} \mathrm{C}$ for $3 \mathrm{~min} ., 15$ amplification cycles at $94^{\circ} \mathrm{C}$ for $0.5 \mathrm{~min}, 67^{\circ} \mathrm{C}$ for $0.5 \mathrm{~min}$, and $72^{\circ} \mathrm{C}$ for $1 \mathrm{~min}$ with a lowered annealing temperature of 0.7 each cycle, and 23 cycles at $94^{\circ} \mathrm{C}$ for $0.5 \mathrm{~min}, 56^{\circ} \mathrm{C}$ for $0.5 \mathrm{~min}$, and $72^{\circ} \mathrm{C}$ for $1 \mathrm{~min}$ followed by 7 -min extension at $72^{\circ} \mathrm{C}$ using a pair of primers, each of which contained three selective nucleotides, in a $20 \mu \mathrm{l}$ aliquot containing $2 \mu \mathrm{l}$ diluted pre-amplification product, $1.4 \mu \mathrm{l} \mathrm{M}$-primer $(10 \mathrm{mM}), 1 \mu \mathrm{l} \mathrm{E}$-primer (10 $\mathrm{mM}$ ), $2.0 \mu \mathrm{l} 10 \times$ PCR buffer, $1.3 \mu \mathrm{l} 25 \mathrm{mM} \mathrm{MgCl}$, $0.2 \mu \mathrm{l} 5 \mathrm{U} / \mu \mathrm{l} \mathrm{Taq}$ polymerase (TaKaRa Biotechnology (Dalian) Co., Ltd.), $1.0 \mu \mathrm{l} 10 \mathrm{~m} M$ solution of mixed dNTPs (Sangon Biotech (Shanghai) Co., Ltd.), and $11.1 \mu \mathrm{l} \mathrm{H}_{2} \mathrm{O}$. Totally 41 pairs of primers were used in the experiment. The amplification products thus obtained were run on a $6 \%$ polyacrylamide gel for $2.5 \mathrm{~h}$ on a sequencer (CBS, USA). Gel images were scanned and manually scored for the presence or absence of bands. The AFLP bands were named after the code of EcoR I/Mse I primer pairs followed by the number of the band.

In total, 24 ISSR primers were used in the analysis of genomic DNAs. Amplifications were performed in 20- $\mu \mathrm{l}$ aliquots of the solution, each of which contained $3 \mu \mathrm{l}$ of a $10 \mathrm{ng} / \mu \mathrm{l}$ template DNA, $2 \mu \mathrm{l} 10 \times$ buffer, $3.25 \mu \mathrm{l}$ $25 \mathrm{mM} \mathrm{MgCl} 2,0.5 \mu \mathrm{l} 25 \mathrm{~m} M$ solution of each dNTP (Sangon Biotech (Shanghai) Co., Ltd.), $0.7 \mu l 10 \mu M$ primer, $0.2 \mu \mathrm{l}$ Taq DNA polymerase (TaKaRa Biotechnology (Dalian) Co., Ltd.) and $10.35 \mu \mathrm{l} \mathrm{H}_{2} \mathrm{O}$. Amplifications were programmed for pre-denaturing at $94^{\circ} \mathrm{C}$ for $5 \mathrm{~min}$, and 35 amplification cycles $\left(94^{\circ} \mathrm{C}\right.$ for $30 \mathrm{~s}$, denaturing for $45 \mathrm{~s}$, and $72^{\circ} \mathrm{C}$ for $90 \mathrm{~s}$ ) followed by 7 -min extension at $72^{\circ} \mathrm{C}$, in which the denaturing temperature varied among primers. Amplification products were resolved by electrophoresis on a gel of $1.6 \%$ agarose at $150 \mathrm{~V}$ for $30 \mathrm{~min}, \mathrm{~EB}$ stained and photographed (Alpha Innotech Corporation, USA). The segregation patterns of ISSR markers were scored and denoted in a way similar to those of RAPD makers.

\section{Map construction and QTL mapping}

Chi-squared tests were performed to check if the markers genotyped follow the Mendelian ratios. The markers with significant departure from Mendelian segregation ratios were excluded from the map construction. A maternal linkage map was constructed using MapMaker version 3.0 [43] following a backcross mapping strategy. The data 
sets of dominant markers were duplicated to allow the detection of repulsion phase between linked markers, indicated by $R$ after the names of markers. The "triple error detection" and the "error detection" features were used to recognize the circumstance in which an event was more probably the result of error than of recombination. These features avoid map expansion [44]. Linkage groups were assigned with thresholds for a minimum LOD (logarithm of the odds) score of 6.0 and a maximal recombination fraction of 0.30 . The markers were ordered using the "Order" command iteratively with a default LOD of 3.0. The first-sequence order was confirmed using the "Ripple" command permuting five markers at a time. All markers that were not ordered in the first pass were placed again using the "Try" command. Linkage maps were generated with the "map" command using the Kosambi mapping function. Maps were drawn with the program MapChart 2.1 [45].

For megagametophyte-generated markers, we used Wu's [18] approach to formulate a mixture likelihood for functional mapping of QTLs that control growth traits. Functional mapping is a dynamic model that was derived to map growth QTLs through integrating growth equations into a mapping framework [28-32]. In this study, growth traits were measured in the first three years of growth. Growth curves that describe juvenile growth are defined by an exponential equation [39], i.e.,

$$
g(t)=a e^{r t}
$$

where $g(t)$ is the growth of a trait at time $t, a$ is the constant and $r$ is the exponent. Thus, by estimating $a$ and $r$ for each QTL genotype, we can test the effect of a QTL on growth curves.

Functional mapping also models the covariance structure of growth traits measured at multiple time points by a statistical approach. In this study, we implemented a first-order autoregressive (AR (1)) model to fit the covariance structure by using the variance and the between-time correlation. To make the data fitted by the stationarity of covariance and correlation assumed for the AR (1) model, we log-transformed raw data of growth. The log-transformation leads to more parallel curves and, thus, increases the feasibility of using the analytically advantageous AR (1) model to analyze the growth data.

If different genotypes at a given QTL correspond to different trajectories, the QTL must affect the differentiation of this trait. Therefore, by estimating the curve parameters $(a, r)$ that define the trait trajectory of each QTL genotype and testing the differences in these parameters among genotypes, we can determine whether a dynamic QTL exists and how it affects the formation and expression of a trait during development.

\section{Funding}

Publication of this work was supported by grants (2008C22003 and 2012C12904-12) from Department of Science and Technology, Zhejiang Province, China, NSF/ IOS-0923975 and "863" Program 2013AA102605 of China.

\section{Competing interests}

The authors declared that they have no competing interests.

\section{Authors' contributions}

Conceived and designed the experiments: YZ RW. Performed the experiments: YZ SY WY. Analyzed the data: SW, WH. Contributed reagents/ materials/analysis tools: YZ WD JC. Wrote the paper: YZ RW.

\section{Declarations}

This article has been published as part of BMC Genetics Volume 15 Supplement 1, 2014: Selected articles from the International Symposium on Quantitative Genetics and Genomics of Woody Plants. The full contents of the supplement are available online at http://www.biomedcentral.com/ bmcgenet/supplements/15/S1.

\section{Authors' details}

${ }^{1}$ The Nurturing Station for the State Key Laboratory of Subtropical Silviculture, Zhejiang Agricultural and Forestry University, Lin'an, Zhejiang 311300, China. ${ }^{2}$ Department of Applied Mathematics Statistics, State University of New York at Stony Brook, Stony Brook, NY 11794, USA. ${ }^{3}$ Department of Preventive Medicine, State University of New York at Stony Brook, Stony Brook, NY 11794, USA. ${ }^{4}$ Center for Statistical Genetics, Pennsylvania State University, Hershey, PA 17033, USA. ${ }^{5}$ Research Institute of Subtropical Forestry, Chinese Academy of Forestry, Fuyang, Zhejiang 311400 , China.

\section{Published: 20 June 2014}

\section{References}

1. Wu RL, Zeng Z-B, McKend SE, O'Malley DM: The case for molecular mapping in forest tree breeding. Plant Breed Rev 2000, 19:41-68.

2. Neale DB, Kremer A: Forest tree genomics: growing resources and applications. Nat Rev Genet 2011, 12:111-122.

3. Lander ES, Botstein D: Mapping Mendelian factors underlying quantitative traits using RFLP linkage maps. Genetics 1989, 121:185-199.

4. Haley CS, Knott SA: A simple regression method for mapping quantitative trait loci in line crosses using flanking markers. Heredity 1992, 69:315-324.

5. Wu R, Ma CX, Casella G: Statistical Genetics of Quantitative Traits Linkage, Maps, and QTL. Springer, New York; 2007.

6. Lynch M, Walsh B: Genetics and Analysis of Quantitative Traits. Sinauer Associates, Sunderland, Massachusetts; 1997.

7. Grattapaglia D, Sederoff R: Genetic linkage maps of Eucalyptus grandis and Eucalyptus urophylla using a pseudo-testcross: Mapping strategy and RAPD markers. Genetics 1994, 137:1121-1137.

8. Hanley S, Barker A, Van Ooijen W, Aldam C, Harris L, Ahman I, Larsson S, Karp A: A genetic linkage map of willow (Salix viminalis) based on AFLP and microsatellite markers. Theor Appl Genet 2002, 105:1087-1096.

9. Pekkinen $M$, Varvio S, Kulju KKH, Kärkkäinen M, Smolander S, ViheräAarnio A, Koski V, Sillanpää MJ: Linkage map of birch, Betula pendula Roth, based on microsatellite and amplified fragment length polymorphisms. Genetics 2005, 48:615-625.

10. Bradshaw HD, Villar M, Watson BD, Otto KG, Stewart S, Stettler RF: Molecular genetics of growth and development in Populus. III. A genetic linkage map of a hybrid poplar composed of RFLP, STS, and RAPD markers. Theor Appl Genet 1994, 89:167-178.

11. Wu RL, Han YF, Hu JJ, Li L, Li ML, Zeng Z-B: An integrated genetic map of Populus based on amplified fragment length polymorphisms. Theor Appl Genet 2000, 100:1249-1256.

12. Gaudet M, Jorge V, Paolucci I, Beritognolo I, Scarascia Mugnozza G, Sabatti M: Genetic linkage maps of Populus nigra L. including AFLPs, SSRs, SNPs, and sex trait. Tree Genet Genom 2008, 4:25-36. 
13. Nelson CD, Kubisiak TL, Stine M, Nance WL: A genetic linkage map of longleaf pine (Pinus palustris Mill.) based on random amplified polymorphic DNAs. J Hered 1994, 85:433-439.

14. Wilcox PL, Amerson HV, Kuhlman EG, Liu BH, O'Malley DO, et al: Detection of a major gene for resistance to fusiform rust disease in loblolly pine by genomic mapping. Proc Natl Acad Sci USA 1996, 93:3859-3864.

15. Maliepaard C, Jansen J, van Ooijen JW: Linkage analysis in a full-sib family of an outbreeding plant species: Overview and consequences for applications. Genet Res 1997, 70:237-250.

16. Wu R, Ma C, Painter I, Zeng Z: Simultaneous maximum likelihood estimation of linkage and linkage phases in outcrossing species. Theor Pop Biol 2002, 61:349-363.

17. Lu Q, Cui YH, Wu RL: A multilocus likelihood approach to joint modeling of linkage, parental diplotype and gene order in a full-sib family. BMC Genet 2004, 5:20.

18. Wu RL: Mapping quantitative trait loci by genotyping haploid tissues. Genetics 1999, 52:1741-1752.

19. Bierhorst DW: Morphology of Vascular Plants. Macmillan, New York; 1971.

20. Kang N, Tang ZX: Studies on the taxonomy of genus Torreya. Bull Bot Res 1995, 15:349-362.

21. He D: DNA extraction and establishment of an AFLP protocol in the construction of a molecular genetic map in $T$. grandis cv. Merrillii. Thesis, Central South Forestry University (In Chinese); 2000.

22. Hu F, Zhang D, Wuyuntana, Tan $x$ : Optimization of the experiment conditions for the randomly amplif ied polymorphism DNA analysis for Torreya grandis. Econ For Res 2002, 20(3):5-7, (In Chinese).Liang D, Wu Y, Zeng Y, Cheng X, Wu S, Tong Z (2007) Establishment of an AFLP system in Torreya grandis J Fujian Forest Sci Tech 34(2): 93-96 (In Chinese).

23. Ye S, Chen G, Zhang H, Liu J, Zeng Y, Wu H: Optimization of an ISSR-PCR system and primer screening for Torreya grandis Fort. ex Lindl. cv. Merrillii Hu. J Zhejiang Forest Coll 2010, 27(1):87-92.

24. Dai Z, Chen L, Tong P: Genetic variation and fingerprinting of Torreya grandis cultivars detected by ISSR markers. Acta Hortic $\operatorname{Sin} 2008$, 35(8):1125-1130, (In Chinese).

25. Liang D, Zhou Q, Shu Y, Zeng Y, Yu W: AFLP-base sexual identification in Torreya grandis. J Zhejiang Forest Coll 2009, 26(1):63-67, (In Chinese).

26. Dai $Z$, Chen $L$, Tong P: RAPD and SCAR markers for sex identification in Torreya grandis. J Fruit Sci 2008, 25(6):856-859, (In Chinese).

27. Ma CX, Gasella G, Wu R: Functional mapping of quantitative trait loci underlying the character process: a theoretical framework. Genetics 2002, 161:1751-1762.

28. Wu R, Lin M: Functional mapping - how to map and study the genetic architecture of dynamic complex traits. Nature Reviews Genetics 2006, 7:229-237.

29. Li Q, Huang Z, Xu M, Wang C, Gai J, Huang Y, Pang X, Wu R: Functional mapping of genotype-environment interactions for soybean growth by a semiparametric approach. Plant Methods 2010, 6:13.

30. Li Y, Wu RL: Functional mapping of growth and development. Biol Rev 2010, 85:207-216.

31. He QL, Berg A, Li Y, Vallejos CE, Wu RL: Modeling genes for plant structure, development and evolution: Functional mapping meets plant ontology. Trends Genet 2010, 26:39-46.

32. Guan $Q$, Yuan M, Yu Z: Early discrimination of karyotype and sexuality for Chinese torreya. Sci Silv Sin 1993, 29(5):389-392, (In Chinese).

33. Zimin A, Stevens KA, Crepeau MW, Holtz-Morris A, Koriabine M, Marcais G, Puiu D, Roberts M, Wegrzyn JL, de Jong PJ, Neale DB, Salzberg SL, Yorke JA, Langley $\mathrm{CH}$ : Sequencing and assembly of the 22-Gb loblolly pine genome. Genetics 2014, 196:875-890.

34. Wegrzyn JL, Liechty JD, Stevens KA, Wu LS, Loopstra CA, Vasquez-Gross HA, Dougherty WM, Lin BY, Zieve JJ, et al: Unique features of the loblolly pine (Pinus taeda L.) megagenome revealed through sequence annotation. Genetics 196:891-909.

35. Wu RL, Ma CX, Lin M, Casella G: A general framework for analyzing the genetic architecture of developmental characteristics. Genetics 2004, 166:1541-1551.

36. Zhao W, Zhu J, Gallo-Meagher M, Wu R: A unified statistical model for functional mapping of environment-dependent genetic expression and genotype $\times$ environment interactions of ontogenetic development. Genetics 2004, 168:1751-1762.
37. Wu R, M CX, Hou W, Corva P, Medrano JF: Functional mapping of quantitative trait loci that interact with the $h g$ mutation to regulate growth trajectories in mice. Genetics 2005, 171(1):239-249.

38. Bertalanffy VL: Quantitative laws for metabolism and growth. Q Rev Biol 1957, 32:217-231.

39. Sillanpää MJ, Pikkuhookana P, Abrahamsson S, Knürr T, Fries A, Lerceteau E, Waldmann P, García-Gil MR: Simultaneous estimation of multiple quantitative trait loci and growth curve parameters through hierarchical Bayesian modeling. Heredity 2012, 108:134-146.

40. Lander ES, Green P, Abrahamson J, Barlow A, Daly M, Lincoln S, Newburg L: MapMaker, an interactive computer package for construction genetic linkage maps of experimental and natural populations. Genomics 1987, 1:174-181.

41. Lincoln SE, Lander ES: Systematic detection of errors in genetic linkage data. Genomics 1992, 14:604-610.

42. Voorrips RE: MapChart: Software for the graphical presentation of linkage maps and QTLs. J Hered 2002, 93:77-78.

doi:10.1186/1471-2156-15-S1-S2

Cite this article as: Zeng et al:: Genetic linkage map construction and QTL identification of juvenile growth traits in Torreya grandis. BMC Genetics 2014 15(Suppl 1):S2.

\section{Submit your next manuscript to BioMed Central and take full advantage of:}

- Convenient online submission

- Thorough peer review

- No space constraints or color figure charges

- Immediate publication on acceptance

- Inclusion in PubMed, CAS, Scopus and Google Scholar

- Research which is freely available for redistribution

Submit your manuscript at www.biomedcentral.com/submit
Biomed Central 